\title{
Antibiotic susceptibility and genomic variations in Staphylococcus aureus associated with Skin and Soft Tissue Infection (SSTI) disease groups
}

\author{
Chih-Hsuan Changchien ${ }^{1}$, Shu-Wun Chen ${ }^{2}$, Ying-Ying Chen ${ }^{1}$ and Chishih Chu ${ }^{2 *}$
}

\begin{abstract}
Background: Staphylococcus aureus is associated with human skin and soft tissue infections (SSTIs); however, the involvement of virulence factors in different clinical presentations is unclear.

Methods: We analyzed methicillin-resistant S. aureus (MRSA) and methicillin-sensitive S. aureus (MSSA) strains from Taiwan to determine correlations among the clinical characteristics of SSTIs, antimicrobial susceptibility and virulence factors of $S$. aureus with specific genetic backgrounds.

Results: We identified 177 MRSA isolates and 130 MSSA isolates among the 307 SSTI-associated S. aureus isolates. Hospital-acquired (HA)- and community-acquired (CA)-MRSA isolates accounted for $61.6 \%$ and $38.4 \%$ of the isolates, respectively. Clinical presentations in SSTI patients differed significantly for the disease groups. Deep-seated MRSA infections presented with higher amputation rate than MSSA infections. MRSA isolates were all susceptible to linezolid, teicoplanin, and vancomycin, and $>94 \%$ of isolates were erythromycin- and clindamycin-resistant. Staphylococcal cassette chromosome (SCCmec) types IV, V, and VII were the most frequent in the CA-MRSA group $(n=68)$; types III, IV and $V$ were the most frequent in the HA-MRSA group $(n=109)$. Panton-Valentine leukocidin (PVL) genes were significantly more frequent in CA-MRSA strains (75.0 \%) than in HA-MRSA (33.0\%) and MSSA (24.6\%) and were found in $66.7 \%(74 / 111)$ strains isolated from the abscess group. Exfoliatin A genes were more common in catheter-related exit-site MSSA infections (37.5\%) compared with other MSSA disease groups $(P<0.05)$. Exfoliatin $B$ and superantigen exotoxin genes were uncommon in all SSTI disease types. Pulsotypes A (ST239), C, and D (ST59) were the predominant MRSA genotypes in deep-seated infections.
\end{abstract}

Conclusions: If not treated appropriately, deep-seated MRSA-associated infections present with higher amputation rates than deep-seated MSSA-associated infections. PVL-positive MRSA strains caused more frequently pus-forming lesions and less bacteremia and invasive diseases. Methods for discriminating CA-MRSA from HA-MRSA strains are now unreliable due to circulation of both ST 239 and ST 59 strains in the community and nosocomial settings. Initial antibiotic treatments should consider MRSA for patients with SSTIs in areas where MRSA is prevalent.

Keywords: MRSA, MSSA, SSTI, MLST, Pulsotype

\footnotetext{
* Correspondence: cschu@mail.ncyu.edu.tw

${ }^{2}$ Department of Microbiology, Immunology, and Biopharmaceuticals,

National Chiayi University, No 300, University Road, Chiayi 60004, Taiwan,

Republic of China

Full list of author information is available at the end of the article
}

\section{Biomed Central}

(c) 2016 The Author(s). Open Access This article is distributed under the terms of the Creative Commons Attribution 4.0 International License (http://creativecommons.org/licenses/by/4.0/), which permits unrestricted use, distribution, and reproduction in any medium, provided you give appropriate credit to the original author(s) and the source, provide a link to the Creative Commons license, and indicate if changes were made. The Creative Commons Public Domain Dedication waiver (http://creativecommons.org/publicdomain/zero/1.0/) applies to the data made available in this article, unless otherwise stated. 


\section{Background}

Staphylococcus aureus is a major pathogen responsible for skin and soft tissue infections (SSTIs) in humans. The number of SSTI episodes with a culture-confirmed pathogen increased from $11 \%$ to $24 \%$ between 1998 and 2009, while the incidence of methicillin-resistant $S$. aureus (MRSA) increased from $5 \%$ in 1998 to $42 \%$ in 2005 before decreasing to $37 \%$ in 2009 [1]. In the USA, colonization by $S$. aureus is high among SSTI patients, particularly that of USA300 MRSA [2]. In Taiwan, the prevalence of MRSA in most of the major hospitals ranged from $53 \%$ to $83 \%$ [3]; MRSA is a major pathogen related to SSTIs [4].

It is considered that community-acquired (CA)-MRSA strains are more virulent than hospital-acquired (HA)MRSA because they possess specific virulence factors and they spread more readily than CA-methicillin-sensitive $S$. aureus (CA-MSSA) [5, 6]. Various extracellular proteins produced by $S$. aureus have been reported to mediate diseases with distinct cutaneous and systemic features. For example, superantigen exotoxin (TSST-1) is associated with staphylococcal toxic shock syndrome, exhibiting desquamative skin rash and multiple organ failure [7]. Exfoliatin A (ETA) and exfoliatin B (ETB) are associated with staphylococcal scalded-skin syndrome with localized and generalized blister formation [8]. Panton-Valentine leukocidin (PVL) and $\gamma$-hemolysin (Hlg) target immune cells, such as polymorphonuclear cells and macrophages, to cause pus-forming SSTIs [9]. However, the actual correlations between $S$. aureus virulence factors and the pathogenesis of different SSTI clinical presentations are unclear.

The surgical timing and the choice of empiric antimicrobials when treating S. aureus-associated SSTI are still controversial because of different clinical presentations and regional variations in their prevalence [10]. In this preliminary study, the clinical characteristics of SSTIs, antimicrobial susceptibilities, and the virulence factors of $S$. aureus strains with specific genetic backgrounds were investigated.

\section{Methods}

\section{Patient characteristics}

This study was performed at the Chiayi Christian Hospital, a 1000-bed teaching hospital in southern Taiwan, between January 2008 and November 2008 and was approved by the research ethics committee of the Chiayi Christian Hospital (097032 and 101051). The medical records of patients diagnosed with SSTI were reviewed, including demographic data, the type of infection, and underlying chronic illnesses (e.g., diabetes mellitus, hypertension, chronic liver disease, coronary artery disease, chronic renal insufficiency, chronic obstructive pulmonary disease, or malignancy). We categorized 307 cases of S. aureus SSTIs on the basis of peculiarity and severity of their clinical presentations into six distinct groups as follows: deep-seated infection (necrotizing fasciitis, osteomyelitis, pyomyositis, and septic arthritis), cutaneous infection (cellulitis, bullous impetigo, furuncle, carbuncle, and staphylococcal scalded-skin syndrome), abscess requiring surgical intervention, postpartum mastitis, catheter-related (peritoneal catheter or intravascular catheter) exit-site infection, or SSTI-related bacteremia. We also documented the microbiological data, appropriateness of empiric antibiotics, number of surgical interventions and reconstructions, need for amputation, length of hospital stay, and the in-hospital mortality rate.

\section{Bacterial isolates}

In total, 307 SSTI-associated S. aureus were identified based on their characteristic colony morphology, Gram staining, and the catalase reaction (Staphaurex Plus, Remel, KS, USA). Blood cultures were processed using a VITEK 2 GP system (BioMerieux Vitek, Hazelwood, MO, USA) in the hospital laboratory. S. aureus was further confirmed by polymerase chain reaction (PCR) to detect the $c l f A, 16 \mathrm{~S}$ rRNA, and nuc genes, as described previously [11]. BCRC 10781 and BCRC 15211 were used as the methicillin-susceptible and -resistant reference strains, respectively. The HA-MRSA and CA-MRSA isolates were defined as described previously [12].

\section{Antimicrobial susceptibility testing}

Antimicrobial susceptibility was tested using the disc diffusion method according to the guidelines of the Clinical and Laboratory Standards Institute [13]. We determined the susceptibility to clindamycin, erythromycin, fusidic acid, linezolid, oxacillin, penicillin, rifampicin, teicoplanin, tetracycline, trimethoprim-sulfamethoxazole, and vancomycin (BBL, BD, USA). Isolates were considered to be susceptible isolates when their zones of inhibition conformed to the intermediate susceptibility category for a given antibiotic.

PCR identification of staphylococcal cassette chromosome (SCCmec) types and genes for virulence factors

SCCmec types I-IV were identified by multiplex PCR amplification of the SCCmec region $[14,15]$. If isolates could not be assigned to types I-IV, they were grouped into SCCmec types V or VII based on the PCR detection of $\operatorname{crC}$ ( $c c r 5)$ homologues [16-18]. Genes for virulence factors, namely PVL, Hlg, TSST-1, ETA, and ETB, were identified by simplex and multiplex PCR amplification using primers, as described previously [19, 20].

\section{Genetic analysis by pulsed field gel electrophoresis (PFGE) and multilocus sequence typing (MLST)}

The genotype of each isolate was identified by SmaIdigested PFGE analysis, and the results were visually 
interpreted as previously described $[21,22]$. The MLST types of 16 CA- and HA-MRSA isolates were identified using the method described by Enright [23] and by reference to MLST databases (http://saureus.mlst.net).

\section{Statistical analysis}

Statistical analyses were performed using SPSS 12.0 (SPSS Inc, Chicago, IL, USA). The Student's $t$-test (two-tailed) was used to compare mean values. The clinical and categorical data for SSTI patients infected with MRSA or MSSA were compared by ANOVA (Duncan's test). $P<0.05$ was considered statistically significant.

\section{Results}

\section{Patient characteristics}

Clinical S. aureus isolates were collected from 307 SSTI patients, among whom 130 (42.3\%) patients were infected by MSSA and $177(57.7 \%)$ by MRSA. CA-MRSA and HA-MRSA infections accounted for 68 (38.4\%) and 109 $(61.6 \%)$ respectively. Abscess requiring surgical intervention $(36.2 \%)$ and cutaneous infection (34.2\%) were the most common clinical features of $S$. aureus-associated SSTI, followed by deep-seated infection (16.9\%), SSTIrelated bacteremia (11.4\%), catheter-related exit-site infection (8.1\%), and mastitis (5.2\%). MRSA was more prevalent in all disease groups than MSSA. The most significant predisposing factor was diabetes mellitus (33.6 \%), followed by chronic renal diseases $(23.5 \%)$ and chronic liver diseases $(9.7 \%)$.

Univariate analyses of selected clinical characteristics of SSTI showed significant differences in the clinical presentations of various disease types, excluding the mortality rate. For example, the deep-seated infection group had higher comorbidity and amputation rates than did the abscess group, and the SSTI-related bacteremia group had the highest mean age and duration of hospitalization (Tables 1 and 2). However, most of the clinical characteristics of MRSA-associated SSTI were similar to those of MSSA-associated SSTIs for each infection type (Table 3), except MRSA-associated deep-seated infections presented with a higher amputation rate than did MSSA-associated ones ( $20.6 \%$ vs. $0, P<0.05)$.

Antimicrobial agents were generally used to treat these SSTIs in both MRSA- and MSSA-infected patients (86.4 \% vs. $78.5 \%$ ). Most patients (93\%) with MSSA infections received an effective empiric antimicrobial agent. However, $78.1 \%$ of the patients with MRSA infections received ineffective empiric antimicrobial therapy, where $\beta$-lactam antimicrobials were mostly used. Vancomycin was initially prescribed to treat $6.2 \%$ of the MRSA infections and $7.7 \%$ of the MSSA infections.

\section{SCCmec typing and antimicrobial susceptibility testing}

The SCCmec types of 177 MRSA isolates are shown in Table 4. The mecA genes were identified in all $(68 / 68)$ CA-MRSA strains, $99.1 \%(108 / 109)$ of HA-MRSA strains, and $2.3 \%(3 / 130)$ of MSSA strains. The major SCCmec types were small-sized SCCmec types IV, V, and VII in CA-MRSA strains, and SCCmec types III, IV, and V in HA-MRSA strains. SCCmec III-carrying isolates were more prevalent in patients with catheter-related exit-site infections (35.3 \%) and SSTI-related bacteremia (34.8 \%) than patients with mastitis $(9.0 \%)$ or abscesses $(8.1 \%)(P$ $<0.05)$. SCCmec VII-carrying isolates were more prevalent in patients with abscesses $(27.4 \%)$ than in those with catheter-related exit-site infection $(0)(P<0.05)$ (Table 5).

The antibiotic resistance patterns differed significantly among the various SCCmec types. The majority of the isolates that contained SCCmec IV, V, or VII elements were susceptible to trimethoprim-sulfamethoxazole (SXT) but were resistant to $\beta$-lactams, erythromycin, and clindamycin. SCCmec type II or III isolates were more resistant to fusidic acid than SCCmec type IV, V, or VII isolates $(P<0.05)$. All $S$. aureus isolates were susceptible to linezolid, teicoplanin, and vancomycin. Most MSSA isolates were susceptible to all antibiotics tested, excluding penicillin. Over 94\% MRSA isolates were resistant to

Table 1 Differences in the clinical characteristics of MRSA-associated SSTIs among disease groups according to univariate analysis

\begin{tabular}{|c|c|c|c|c|c|c|c|}
\hline $\begin{array}{l}\text { Clinical } \\
\text { characteristics }\end{array}$ & $\begin{array}{l}\text { Deep-seated } \\
\text { infection }(n=34)\end{array}$ & $\begin{array}{l}\text { Cutaneous } \\
\text { infection }(n=54)\end{array}$ & Abscess $(n=62)$ & Mastitis $(n=11)$ & $\begin{array}{l}\text { SSTI-related } \\
\text { bacteremia } \\
(n=23)\end{array}$ & $\begin{array}{l}\text { Catheter-related } \\
\text { exit-site infection } \\
(n=17)\end{array}$ & $P$-value \\
\hline Mean age (years) & $58.4^{\mathrm{ab}}$ & $50.6^{\mathrm{bc}}$ & $39.7^{\text {cd }}$ & $30.7^{d}$ & $68.3^{\mathrm{a}}$ & $60.8^{\mathrm{ab}}$ & $<0.001$ \\
\hline Mean comorbidities & $2.2^{\mathrm{b}}$ (Range $0-5$ ) & $1.9^{\mathrm{b}}$ (Range 0-6) & $0.9^{c}$ (Range $0-5$ ) & $0.1^{\complement}$ (Range $0-1$ ) & $3.4^{\mathrm{a}}$ (Range 0-7) & $3.5^{\mathrm{a}}$ (Range $0-7$ ) & $<0.001$ \\
\hline Mean operative procedure & $1.2^{\mathrm{a}}$ (Range $0-3$ ) & $0^{c}$ (Range $0-1$ ) & $1.2^{\mathrm{a}}$ (Range $0-6$ ) & $0.1^{\mathrm{bc}}$ (Range $\left.0-1\right)$ & $0.5^{\mathrm{b}}$ (Range $0-2$ ) & $0.1^{\mathrm{bc}}$ (Range $0-2$ ) & $<0.001$ \\
\hline Reconstructive surgery (\%) & $4(11.8)^{a}$ & $0(0)^{b}$ & $1(1.6)^{b}$ & $0(0)^{b}$ & $0(0)^{b}$ & $0(0)^{b}$ & $<0.01$ \\
\hline Amputation (\%) & $7(20.6)^{a}$ & $0(0)^{b}$ & $2(3.2)^{b}$ & $0(0)^{b}$ & $3(13.4)^{\mathrm{ab}}$ & $0(0)^{b}$ & $<0.001$ \\
\hline Mean hospitalization days & $16.9^{\mathrm{ab}}$ & $9.1^{\mathrm{b}}$ & $9.6^{b}$ & $0.5^{c}$ & $19.2^{\mathrm{a}}$ & $13.3^{\mathrm{ab}}$ & $<0.01$ \\
\hline Mortality (\%) & $0(0)$ & $3(5.6)$ & $0(0)$ & $0(0)$ & $1(4.3)$ & $0(0)$ & 0.248 \\
\hline
\end{tabular}

${ }^{\mathrm{ab}}$ Values in a row followed by different letters indicate significant difference between groups; $P<0.05$ 
Table 2 Differences in the clinical characteristics of MSSA-associated SSTI among disease groups according to univariate analysis

\begin{tabular}{|c|c|c|c|c|c|c|c|}
\hline $\begin{array}{l}\text { Clinical } \\
\text { characteristics }\end{array}$ & $\begin{array}{l}\text { Deep-seated } \\
\text { infection }(n=18)\end{array}$ & $\begin{array}{l}\text { Cutaneous } \\
\text { infection }(n=51)\end{array}$ & Abscess $(n=49)$ & Mastitis $(n=5)$ & $\begin{array}{l}\text { SSTI-related } \\
\text { bacteremia } \\
(n=12) \\
\end{array}$ & $\begin{array}{l}\text { Catheter-related } \\
\text { exit-site infection } \\
(n=8)\end{array}$ & $P$-value \\
\hline Mean age (years) & $53.7^{\mathrm{ab}}$ & $48.0^{\mathrm{ab}}$ & $39.5^{b c}$ & $27.0^{c}$ & $59.9^{a}$ & $52.9^{\mathrm{ab}}$ & $<0.05$ \\
\hline Mean comorbidities & $2.3^{\mathrm{ab}}$ (Range 0-5) & $1.5^{\mathrm{bc}}$ (Range 0-6) & $0.8^{\mathrm{cd}}$ (Range $0-4$ ) & $0^{d}$ (Range 0) & 3.0 (Range 1-7) & $3.1^{\mathrm{a}}$ (Range 0-7) & $<0.001$ \\
\hline $\begin{array}{l}\text { Mean operative } \\
\text { procedure }\end{array}$ & $1.6^{\mathrm{a}}$ (Range $0-3$ ) & $0.02^{\mathrm{e}}$ (Range $0-1$ ) & 1. $2^{\mathrm{ab}}$ (Range 1-3) & $0.2^{\text {de }}$ (Range $0-1$ ) & $0.6^{\mathrm{cd}}$ (Range $0-3$ ) & $0.9^{\mathrm{bc}}$ (Range $0-2$ ) & $<0.01$ \\
\hline $\begin{array}{l}\text { Reconstructive } \\
\text { surgery (\%) }\end{array}$ & $4(22.2)^{a}$ & $0(0)^{b}$ & $2(4.1)^{b}$ & $0(0)^{b}$ & $0(0)^{b}$ & $0(0)^{b}$ & $<0.05$ \\
\hline Amputation (\%) & $0(0)$ & $0(0)$ & $0(0)$ & $0(0)$ & $0(0)$ & $0(0)$ & NA \\
\hline $\begin{array}{l}\text { Mean hospitalization } \\
\text { days }\end{array}$ & $13.2^{\mathrm{ab}}$ & $6.9^{b}$ & $7.7^{\mathrm{ab}}$ & $4.0^{\mathrm{b}}$ & $18.3^{\mathrm{a}}$ & $8.4^{\mathrm{ab}}$ & $<0.05$ \\
\hline Mortality (\%) & $0(0)$ & $1(2.0)$ & $1(2.0)$ & $0(0)$ & $0(0)$ & $0(0)$ & 0.974 \\
\hline
\end{tabular}

ab Values in a row followed by different letters indicate significant difference between groups; $P<0.05$

erythromycin and clindamycin. Compared with CAMRSA isolates, HA-MRSA isolates were more resistant to fusidic acid and SXT (Fig. 1).

\section{Prevalence of PVL, Hlg, TSST-1, ETA, and ETB genes}

The PVL gene was identified in $38.8 \% \mathrm{~S}$. aureus isolates and was significantly more frequent in CA-MRSA strains $(75.0 \%, 51 / 68)$ than in HA-MRSA $(33.0 \%, 36 / 109)$ and MSSA strains $(24.6 \%, 32 / 130)(P<0.01)$ (Table 4). Irrespective of the methicillin-resistance phenotype, PVL genes were detected most frequently in abscesses, i.e., $66.7 \%$ (74/111), followed by mastitis, cutaneous infections, deep-seated infections, bacteremia, and catheter-related infections. Among all of the SSTI cases, only one ETB gene was identified from a patient with staphylococcal scalded-skin syndrome. Compared with other MSSA disease groups, ETA genes were more common in catheterrelated exit-site MSSA infections $(37.5 \%)(P<0.05)$. All the MRSA isolates possessed $\mathrm{Hlg}$ genes, which were otherwise only present in $92.3 \%$ of the MSSA isolates
$(P<0.01)$. The TSST-1 gene was seldom identified in any disease type (Table 6).

\section{PFGE analysis}

PFGE analysis separated 32 MRSA isolates from deepseated infections into eight pulsotypes, among which pulsotypes A, C, and D accounted for $78.1 \%$ of the isolates. Associations between pulsotypes and SCCmec types were determined for pulsotype A with SCCmec type II

I (100 \%) and pulsotype C with SCCmec type IV (88.9\%). Pulsotype D contained diverse SCCmec elements (types II, III, V, VII, and nontypeable SCCmec elements), but SCCmec type V was the major type (40\% of pulsotype D). MLST analysis identified pulsotype A as ST239 and pulsotype C as ST59.

\section{Discussion}

S. aureus-associated SSTIs exhibit diverse clinical presentations, mediated by various bacterial toxins and host susceptibility to some extent. Localized cutaneous infections in healthy individuals may resolve spontaneously

Table 3 Differences in clinical characteristics between MRSA- and MSSA-associated disease groups according to univariate analysis

\begin{tabular}{|c|c|c|c|c|c|c|c|c|c|c|c|c|c|c|}
\hline \multirow[t]{2}{*}{$\begin{array}{l}\text { Clinical } \\
\text { characteristics }\end{array}$} & \multicolumn{2}{|c|}{$\begin{array}{l}\text { Deep-seated } \\
\text { infection }\end{array}$} & \multicolumn{2}{|c|}{$\begin{array}{l}\text { Cutaneous } \\
\text { infection }\end{array}$} & \multicolumn{2}{|l|}{ Abscess } & \multicolumn{2}{|l|}{ Mastitis } & \multicolumn{2}{|c|}{$\begin{array}{l}\text { SSTI-related } \\
\text { bacteremia }\end{array}$} & \multicolumn{2}{|c|}{$\begin{array}{l}\text { Catheter-related } \\
\text { exit-site infection }\end{array}$} & \multicolumn{2}{|l|}{$P$-value } \\
\hline & $\begin{array}{l}\text { MRSA } \\
(n=34)\end{array}$ & $\begin{array}{l}\text { MSSA } \\
(n=18)\end{array}$ & $\begin{array}{l}\text { MRSA } \\
(n=54)\end{array}$ & $\begin{array}{l}\text { MSSA } \\
(n=51)\end{array}$ & $\begin{array}{l}\text { MRSA } \\
(n=62)\end{array}$ & $\begin{array}{l}\text { MSSA } \\
(n=49)\end{array}$ & $\begin{array}{l}\text { MRSA } \\
(n=11)\end{array}$ & $\begin{array}{l}\text { MSSA } \\
(n=5)\end{array}$ & $\begin{array}{l}\text { MRSA } \\
(n=23)\end{array}$ & $\begin{array}{l}\text { MSSA } \\
(n=12)\end{array}$ & $\begin{array}{l}\text { MRSA } \\
(n=17)\end{array}$ & $\begin{array}{l}\text { MSSA } \\
(n=8)\end{array}$ & MRSA & MSSA \\
\hline Mean age (years) & 58.4 & 53.7 & 50.6 & 48.0 & 39.7 & 39.5 & 30.7 & 27.0 & 68.3 & 59.9 & 60.8 & 52.9 & $<0.001$ & $<0.05$ \\
\hline Mean comorbidities & 2.2 & 2.3 & 1.9 & 1.5 & 0.9 & 0.8 & 0.1 & 0 & 3.4 & 3.0 & 3.5 & 3.1 & $<0.001$ & $<0.001$ \\
\hline $\begin{array}{l}\text { Mean operative } \\
\text { procedure }\end{array}$ & 1.2 & 1.6 & 0 & 0.02 & 1.2 & 1.2 & 0.1 & 0.2 & 0.5 & 0.6 & 0.1 & 0.9 & $<0.001$ & $<0.01$ \\
\hline $\begin{array}{l}\text { Reconstructive } \\
\text { surgery (\%) }\end{array}$ & $4(11.8)$ & $4(22.2)$ & $0(0)$ & $0(0)$ & $1(1.6)$ & $2(4.1)$ & $0(0)$ & $0(0)$ & $0(0)$ & $0(0)$ & $0(0)$ & $0(0)$ & $<0.01$ & $<0.05$ \\
\hline Amputation (\%) & $7(20.6)^{*}$ & $0(0)$ & $0(0)$ & $0(0)$ & $2(3.2)$ & $0(0)$ & $0(0)$ & $0(0)$ & $3(13.4)$ & $0(0)$ & $0(0)$ & $0(0)$ & $<0.001$ & NA \\
\hline $\begin{array}{l}\text { Mean hospitalization } \\
\text { days }\end{array}$ & 16.9 & 13.2 & 9.1 & 6.9 & 9.6 & 7.7 & 0.5 & 4.0 & 19.2 & 18.3 & 13.3 & 8.4 & $<0.01$ & $<0.05$ \\
\hline Mortality (\%) & $0(0)$ & $0(0)$ & $3(5.6)$ & $1(2.0)$ & $0(0)$ & $1(2.0)$ & $0(0)$ & $0(0)$ & $1(4.3)$ & $0(0)$ & $0(0)$ & $0(0)$ & 0.248 & 0.974 \\
\hline
\end{tabular}

*Indicates a significant difference between the MRSA and MSSA groups; $P<0.05$ 
Table 4 Differences in prevalence of SCCmec types and virulence factors among CA-MRSA, HA-MRSA, and MSSA groups

\begin{tabular}{|c|c|c|c|c|}
\hline $\begin{array}{l}\text { SCCmec types } \\
\text { and virulence } \\
\text { factors }\end{array}$ & $\begin{array}{l}\text { CA-MRSA } \\
(n=68)\end{array}$ & $\begin{array}{l}\text { HA-MRSA } \\
(n=109)\end{array}$ & $\begin{array}{l}\text { MSSA } \\
(n=130)\end{array}$ & $P$-value \\
\hline \multicolumn{5}{|l|}{ sccmec } \\
\hline Type II & $1(1.4 \%)^{c}$ & $4(3.6 \%)^{b}$ & $0(0)$ & 0.393 \\
\hline Type III & $4(5.9 \%)^{c}$ & $27(24.8 \%)^{a}$ & $0(0)$ & $<0.01$ \\
\hline Type IV & $20(29.4 \%)^{a}$ & $25(22.9 \%)^{\mathrm{a}}$ & $0(0)$ & 0.339 \\
\hline Type V & $21(30.9 \%)^{a}$ & $29(26.6 \%)^{a}$ & $0(0)$ & 0.541 \\
\hline Type VII & $15(22.1 \%)^{a b}$ & $14(12.8 \%)^{b}$ & $0(0)$ & 0.108 \\
\hline Nontypeable & $7(10.3 \%)^{b c, y}$ & $10(9.2 \%)^{b, y}$ & $130(100 \%)^{x}$ & $<0.01$ \\
\hline mecA & $68(100 \%)^{a}$ & $108(99.1 \%)^{a}$ & $3(2.3 \%)^{b}$ & $<0.01$ \\
\hline \multicolumn{5}{|l|}{ Virulence factors } \\
\hline PVL & $51(75.0 \%)^{x}$ & $36(33.0 \%)^{y}$ & $32(24.6 \%)^{y}$ & $<0.01$ \\
\hline $\mathrm{Hlg}$ & $68(100 \%)^{x}$ & $109(100 \%)^{x}$ & $120(92.3 \%)^{y}$ & $<0.01$ \\
\hline TSST-1 & $4(5.8 \%)$ & $4(3.7 \%)$ & 7 (4.6 \%) & 0.725 \\
\hline ETA & $14(22.1 \%)^{y}$ & $35(29.6 \%)^{x}$ & $23(19.0 \%)^{y}$ & $<0.01$ \\
\hline ETB & $1(1.4 \%)$ & $0(0)$ & $0(0)$ & 0.09 \\
\hline
\end{tabular}

${ }^{\mathrm{ab}}$ Different letters in the same column indicate significant differences between groups; $P<0.05$

${ }^{x y}$ Different letters in the same row indicate significant differences between groups; $P<0.05$

using topical antimicrobials. However, the majority of abscess-forming lesions usually require surgical intervention. Aggressive antimicrobial treatment of deep-seated infections and SSTI-related bacteremia is crucial for survival. Compared with MSSA infections, MRSA infections may present with different clinical characteristics and outcomes for deep-seated infections, bacteremia, catheter-related infections, and mastitis [24-26]. It has been reported that patients with MRSA bacteremia have a significantly higher mortality rate (15-60\%) and longer hospitalization duration compared with those with MSSA bacteremia [27]. By contrast, Miller et al. reported that most clinical characteristics of MRSA-associated SSTI could not be used as markers to distinguish MSSA-infected patients [28]. Our results indicate that deep-seated MRSA infections presented with a higher amputation rate than MSSA infections
(20.6 \% vs. 0 \%) (Table 3). It should be noted that most patients $(78.1 \%)$ with MRSA infections received ineffective empiric antimicrobial therapy. Thus, the correlation between diverse clinical outcomes and inappropriate empiric therapy for severe infections requires further study.

Catheter-related exit-site infection is a peculiar nosocomial infection, which is usually associated with bacterial colonization and biofilm formation in SSTIs, and has been reported as the most common source of $S$. aureus bacteremia, with equal proportions of MSSA and MRSA infection [29]. Here, patients with catheterrelated exit-site MRSA infections were more prevalent and had more concurrent bacteremia (64.7 \% vs. 0$)$ compared with MSSA infections, suggesting a greater prevalence of MRSA in our hospital.

In general, $S$. aureus, $\beta$-hemolytic streptococcus, Escherichia coli, and Bacteroides spp. have been isolated from patients with postpartum mastitis. Among the mastitisassociated MRSA isolates obtained in this investigation, 10/11 (90.9 \%) were classified as HA-MRSA strains, but their antimicrobial resistance patterns and PCR results indicated that most isolates possessed the characteristics of CA-MRSA strains.

According to the isolates analyzed by PFGE, the predominant MRSA genotypes were pulsotypes A, C, and D. Pulsotype A isolates related to ST 239 are the major HAMRSA clones in Taiwan [30], whereas pulsotype C and D isolates related to ST 59 are the prevalent clones of CAMRSA in Taiwan $[3,31]$. However, we identified both ST 239 and ST 59 strains from CA and HA-SSTI patients, thereby implying that both strains are circulating concomitantly in community and nosocomial settings.

It was notable that there was a significant association between PVL and MRSA, particularly in cutaneous abscess compared with bacteremia and invasive illnesses. These findings suggest that PVL-positive strains have a higher tendency to develop pus-forming lesions that often require surgical drainages. PVL-positive isolates were significantly more prevalent among the CA-MRSA strains compared with MSSA strains, as described previously [32], thereby reflecting the consequences of the widespread use of $\beta$ -

Table 5 Differences in the prevalence of SCCmec types and virulence factors of MRSA among disease groups

\begin{tabular}{|c|c|c|c|c|c|c|c|}
\hline sccmec type & $\begin{array}{l}\text { Deep-seated } \\
\text { infection }(n=34)\end{array}$ & $\begin{array}{l}\text { Cutaneous } \\
\text { infection }(n=54)\end{array}$ & Abscess $(n=62)$ & Mastitis $(n=11)$ & $\begin{array}{l}\text { SSTI-related } \\
\text { bacteremia } \\
(n=23)\end{array}$ & $\begin{array}{l}\text { Catheter-related } \\
\text { exit-site infection } \\
(n=17)\end{array}$ & $P$-value \\
\hline Type II & 2 (5.9\%) & 2 (3.7 \%) & $1(1.6 \%)$ & $0(0)$ & $0(0)$ & $0(0)$ & 0.608 \\
\hline Type III & $9(26.5 \%)^{\mathrm{ab}}$ & $10(18.5 \%)^{\mathrm{ab}}$ & $5(8.1 \%)^{b}$ & $1(9.0 \%)^{b}$ & $8(34.8 \%)^{a}$ & $6(35.3 \%)^{a}$ & $<0.05$ \\
\hline Type IV & $9(26.5 \%)$ & 14 (25.9\%) & 14 (22.6 \%) & $4(36.4 \%)$ & $6(26.1 \%)$ & 4 (23.5 \%) & 0.936 \\
\hline Type V & 7 (20.5 \%) & 17 (31.5 \%) & 15 (24.2 \%) & $5(45.5 \%)$ & $4(17.4 \%)$ & $6(35.3 \%)$ & 0.294 \\
\hline Type VII & $4(11.8 \%)^{\mathrm{ab}}$ & $8(14.8 \%)^{\mathrm{ab}}$ & $17(27.4 \%)^{a}$ & $1(9.0 \%)^{a b}$ & $3(13.0 \%)^{\mathrm{ab}}$ & $0(0)^{b}$ & $<0.05$ \\
\hline Non-typeable & $3(8.8 \%)$ & $3(5.0 \%)$ & 10 (16.1\%) & $0(0)$ & 2 (8.7 \%) & 1 (5.9\%) & 0.101 \\
\hline
\end{tabular}

ab Values in a row followed by different letters indicate significant differences between groups; $P<0.05$ 


\section{- CA-MRSA $\square$ HA-MRSA $\square$ MSSA}

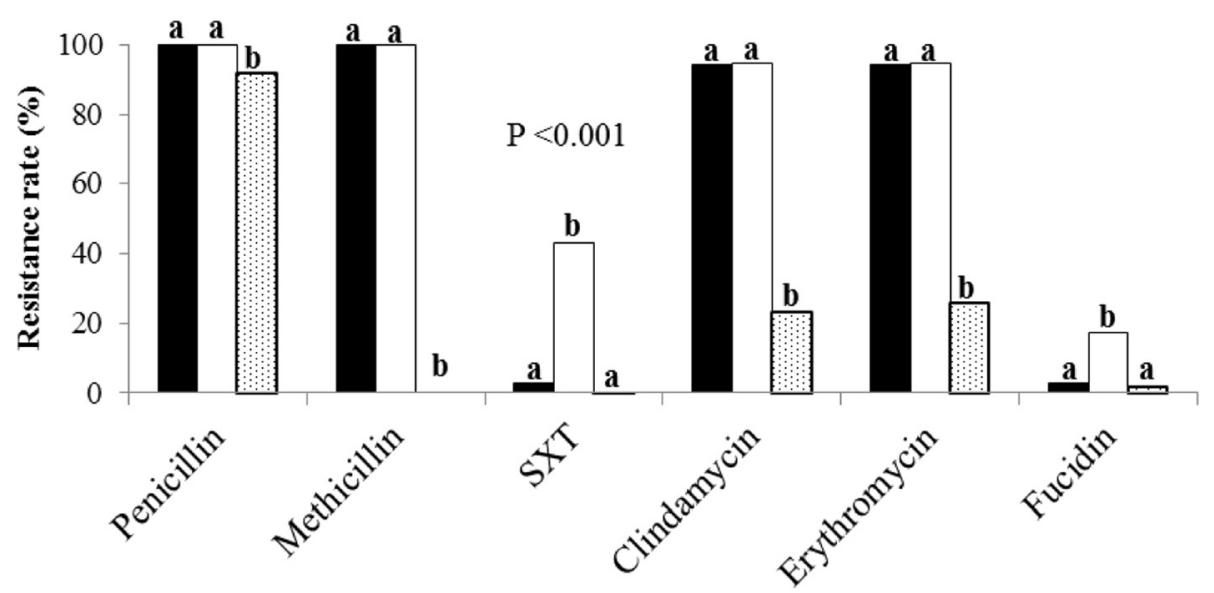

Fig. 1 Antimicrobial susceptibility of CA-MRSA, HA-MRSA, and MSSA. Different letters (a and b) indicate significant differences between groups; $P<0.05$

lactam antibiotics, leading to the selection of a few restricted PVL-positive MRSA strains. Furthermore, PVL genes were identified in both CA- and HA-MRSA strains that possessed SCCmec type III, although SCCmec type IV isolates were dominant in both the CA- and HA-MRSA groups (Table 4). Our results suggest that the SCCmec types and the presence of PVL genes are not useful molecular markers for distinguishing between CA- and HAMRSA strains.

TSST-1, ETA, and ETB are reportedly the major virulence factors associated with some peculiar skin and systemic syndromes in clinical settings. The low carriage rate of these genes in S. aureus isolates from SSTI patients could explain the low incidence of staphylococcal toxic shock syndrome and staphylococcal scalded-skin syndrome in the present study. Diverse skin and systemic presentations of various disease types of SSTI may be correlated with other exotoxin genes or combinations of virulence factors. The $m e c A$ gene was not found in an MRSA isolate in this study, which could be related to diverse resistance mechanisms, e.g., the production of $\beta$ lactamase or other unidentified factors that may contribute to resistance in MRSA [33]. Furthermore, three MSSA isolates that possessed the $m e c A$ gene may have been derived from a $m e c A$-positive MRSA strain subpopulation with a heterogeneous resistance phenotype that cannot be detected by traditional susceptibility testing [34].

The treatment of SSTIs involves topical agents, surgical intervention, or oral or parenteral antimicrobial therapy. Recent reports and the present study demonstrate the high impact of MRSA in SSTIs [35]. Uncomplicated skin abscesses are curable by surgical drainage alone; antimicrobials are not necessary according to the current guidelines. In areas with a high prevalence of MRSA infections, empiric antimicrobial treatment should consider the possibility of MRSA infection in complicated SSTIs and immunocompromised individuals. CA-MRSA strains with type IV SCCmec elements are more susceptible to a variety of non- $\beta$-lactam antimicrobials than are HA-MRSA strains [36]; antimicrobial susceptibility patterns have been used to discriminate CA-MRSA and HA-MRSA strains. However, this approach is now unreliable because CA-MRSA may also acquire resistance to non- $\beta$-lactam antibiotics [37]. Clindamycin has been

Table 6 Differences in virulence factors between MRSA and MSSA among disease groups

\begin{tabular}{|c|c|c|c|c|c|c|c|c|c|c|c|c|}
\hline \multirow[t]{2}{*}{$\begin{array}{l}\text { Virulence } \\
\text { factor }\end{array}$} & \multicolumn{2}{|c|}{ Deep-seated infection } & \multicolumn{2}{|c|}{ Cutaneous infection } & \multicolumn{2}{|l|}{ Abscess } & \multicolumn{2}{|l|}{ Mastitis } & \multicolumn{2}{|c|}{ SSTI-related bacteremia } & \multicolumn{2}{|c|}{$\begin{array}{l}\text { Catheter-related } \\
\text { exit-site infection }\end{array}$} \\
\hline & $\begin{array}{l}\text { MRSA } \\
(n=34)\end{array}$ & $\begin{array}{l}\text { MSSA } \\
(n=18)\end{array}$ & $\begin{array}{l}\text { MRSA } \\
(n=54)\end{array}$ & $\begin{array}{l}\text { MSSA } \\
(n=51)\end{array}$ & $\begin{array}{l}\text { MRSA } \\
(n=62)\end{array}$ & $\begin{array}{l}\text { MSSA } \\
(n=49)\end{array}$ & $\begin{array}{l}\text { MRSA } \\
(n=11)\end{array}$ & $\begin{array}{l}\text { MSSA } \\
(n=5)\end{array}$ & $\begin{array}{l}\text { MRSA } \\
(n=23)\end{array}$ & $\begin{array}{l}\text { MSSA } \\
(n=12)\end{array}$ & $\begin{array}{l}\text { MRSA } \\
(n=17)\end{array}$ & $\begin{array}{l}\text { MSSA } \\
(n=8)\end{array}$ \\
\hline PVL & 7 (20.6 \%) & $1(5.6 \%)$ & $27(50.0 \%)^{*}$ & $4(7.8 \%)$ & 49 (79.0 \%) & $25(51.0 \%)$ & $5(45.5 \%)$ & $2(40.0 \%)$ & $3(13.0 \%)$ & $0(0)$ & 1 (5.9\%) & $0(0)$ \\
\hline $\mathrm{Hlg}$ & 34 (100 \%) & 17 (94.4 \%) & $54(100 \%)$ & 47 (92.2 \%) & 62 (100 \%) & 46 (93.9 \%) & 11 (100\%) & $4(80.0 \%)$ & $23(100 \%)$ & 12 (100\%) & 17 (100 \%) & 7 (87.5 \%) \\
\hline TSST-1 & $4(11.8 \%)$ & $0(0)$ & $2(3.7 \%)$ & $2(3.9 \%)$ & $2(3.2 \%)$ & $5(10.2 \%)$ & $0(0)$ & $0(0)$ & $1(4.3 \%)$ & $1(8.3 \%)$ & $0(0)$ & $1(12.5 \%)$ \\
\hline ETA & $7(20.6 \%)$ & $4(22.2 \%)$ & $15(27.8 \%)$ & $12(23.5 \%)$ & $18(29.6 \%)$ & $2(4.1 \%)$ & $3(27.3 \%)$ & $1(20.0 \%)$ & $5(21.7 \%)$ & $3(25.0 \%)$ & $5(29.4 \%)$ & $3(37.5 \%)$ \\
\hline ETB & $0(0)$ & $0(0)$ & 1 (1.9\%) & $0(0)$ & $0(0)$ & $0(0)$ & $0(0)$ & $0(0)$ & $0(0)$ & $0(0)$ & $0(0)$ & $0(0)$ \\
\hline
\end{tabular}

*Indicates a significant difference between MRSA and MSSA groups; $P<0.05$ 
used as an option for staphylococcal SSTIs due to its good distribution in skin and wound exudates [38]. However, we found that erythromycin and clindamycin resistance were much more frequent (over $94 \%$ ) in both CA- and HA-MRSA isolates than those reported recently from different countries [39]. The treatment guidelines for MRSA infections should be adjusted according to the currently defined efficacy of non- $\beta$-lactam antimicrobials. For complicated SSTIs, the treatment of patients with appropriate initial antimicrobials is associated with a statistically significant impact on the cure rate [40]. According to the susceptibility tests in the present study, SXT appears to be an appropriate empiric oral antimicrobial for treating CAMRSA infections, whereas fusidic acid is more suitable for treating both CA- and HA-MRSA infections (Fig. 1). Vancomycin is warranted only for empiric use when treating deep-seated, life-threatening MRSA infections.

\section{Conclusions}

MRSA is an important emerging pathogen in SSTIs. Most of the clinical characteristics of MRSA-associated SSTIs are similar to those of MSSA-associated SSTIs, except for the higher amputation rate in deep-seated MRSA infections. We found that PVL-positive strains had a higher tendency to cause pus-forming lesions, whereas they were rarely associated with bacteremia and invasive diseases. ETB and TSST-1 genes were identified only rarely in various SSTI disease types. The previously employed criteria and antimicrobial susceptibility patterns for discriminating CA- and HA-MRSA strains are now unreliable because both ST 239 (major clone of HA-MRSA) and ST 59 (major clone of CA-MRSA) strains are circulating concomitantly in community and nosocomial settings in Taiwan. Early surgical drainage of pus-forming lesions and appropriate antimicrobials for invasive infections are mandatory for SSTI treatment. If indicated, the initial empiric antimicrobial treatment should consider MRSA for patients with SSTIs in areas where MRSA is prevalent.

\section{Abbreviations \\ CA-MRSA, community-acquired methicillin-resistant Staphylococcus aureus; CC, clindamycin; CIP, ciprofloxacin; CLSI, Clinical and Laboratory Standards Institute; ETA, exfoliatin A; ETB, exfoliatin B; ERY, erythromycin; FA, fusidic acid; GM, gentamicin; HA-MRSA, hospital-acquired MRSA; Hlg, Y-hemolysin; LZD, linezolid; MLST, multilocus sequence typing; MSSA, methicillin-susceptible Staphylococcus aureus; P, penicillin; PFGE, pulsed field gel electrophoresis; PVL, Panton-Valentine leukocidin; RA, rifampicin; SCCmec, Staphylococcal Cassette Chromosome mec; SSTI, skin and soft tissue infection; SXT, trimethoprim-sulfamethoxazole; TE, tetracycline; TEC, teicoplanin}

\section{Acknowledgements}

The authors would like to thank the Chiayi Christian Hospital for financially supporting this research.

\section{Funding}

This work was supported by the Chiayi Christian Hospital under Contract R101-26. The funders had no role in the design of the study and collection, analysis, and interpretation of data and in writing the manuscript

\section{Availability of data and materials}

We declare that the data supporting the conclusions of this article are fully described within the article.

\section{Authors' contributions}

$\mathrm{CHC}$ and $\mathrm{CC}$ took initiative in developing the research project and manuscript preparation. YYC and SWC participated in the design, laboratory work, and data analysis. All authors read and approved the final manuscript.

\section{Competing interests}

The authors declare that they have no competing interests.

\section{Consent for publication}

Not applicable

\section{Ethics approval and consent to participate}

The study was approved by the research ethics board at the Chiayi Christian hospital (reference number: 097032). Since no patient contact or intervention was carried out, the need for informed consent was waived.

\section{Author details}

'Department of Plastic and Reconstructive Surgery, Chiayi Christian Hospital, 539 Jhongsiao Rd., Chiayi City 60002, Taiwan, Republic of China.

${ }^{2}$ Department of Microbiology, Immunology, and Biopharmaceuticals, National Chiayi University, No 300, University Road, Chiayi 60004, Taiwan, Republic of China.

Received: 22 March 2016 Accepted: 7 June 2016

Published online: 10 June 2016

\section{References}

1. Ray GT, Suaya JA, Baxter R. Microbiology of skin and soft tissue infections in the age of community-acquired methicillin-resistant Staphylococcus aureus. Diagn Microbiol Infect Dis. 2013;76(1):24-30.

2. Kumar N, David MZ, Boyle-Vavra S, Sieth J, Daum RS. High Staphylococcus aureus colonization prevalence among patients with skin and soft tissue infections and controls in an urban emergency department. J Clin Microbiol. 2015;53(3):810-5.

3. Chen FJ, Lauderdale TL, Huang IW, Lo HJ, Lai JF, Wang HY, et al. Methicillinresistant Staphylococcus aureus in Taiwan. Emerg Infect Dis. 2005;11(11): 1760-3.

4. Chou YH, Lee MS, Lin RY, Wu CY. Risk factors for methicillin-resistant Staphylococcus aureus skin and soft-tissue infections in outpatients in Taiwan. Epidem Infect. 2015;143(4):749-53.

5. Boyle-Vavra S, Daum RS. Community-acquired methicillin-resistant Staphylococcus aureus: the role of Panton-Valentine leukocidin. Lab Invest. 2007;87(1):3-9.

6. Davis SL, Perri MB, Donabedian SM, Manierski C, Singh A, Vager D, et al. Epidemiology and outcomes of community-associated methicillin- resistant Staphylococcus aureus infection. J Clin Microbiol. 2007;45(6):1705-11.

7. Warner JE, Onderdonk AB. Diversity of toxic shock syndrome toxin 1positive Staphylococcus aureus isolates. Appl Environ Microbiol. 2004;70(11): 6931-5.

8. Hanakawa Y, Schechter NM, Lin C, Garza L, Li H, Yamaguchi T, et al. Molecular mechanisms of blister formation in bullous impetigo and staphylococcal scalded skin syndrome. J Clin Invest. 2002;110(1):53-60.

9. Diep BA, Sensabaugh GF, Somboona NS, Carleton HA, Perdreau-Remington F. Widespread skin and soft-tissue infections due to two methicillin-resistant Staphylococcus aureus strains harboring the genes for Panton-Valentine leucocidin. J Clin Microbiol. 2004;42(5):2080-4.

10. Hammond SP, Baden LR. Management of skin and soft-tissue infection polling results. N Engl J Med. 2008;359(15):e20.

11. Mason WJ, Blevins JS, Beenken K, Wibowo N, Ojha N, Smeltzer MS. Multiplex PCR protocol for the diagnosis of staphylococcal infection. J Clin Microbiol. 2001:39(9):3332-8.

12. Fridkin SK, Hageman JC, Morrison M, Sanza LT, Como-Sabetti K, Jernigan JA, et al. Methicillin-resistant Staphylococcus aureus disease in three communities. N Engl J Med. 2005;352(14):1436-44.

13. CLSI: Clinical and Laboratory Standards Institute. Performance Standards for Antimicrobial Disk Susceptibility Tests; approved standard, 9th ed. 2006:M2-A9. 
14. Oliveira DC, Lencastre H. Multiplex PCR strategy for rapid identification of structural types and variants of the mec element in methicillin-resistant Staphylococcus aureus. Antimicrob Agents Chemother. 2002;46(7):2155-61.

15. Oliveira DC, Milheirico $\mathrm{C}$, de Lencastre $\mathrm{H}$. Redefining a structural variant of staphylococcal cassette chromosome mec, SCCmec Type VI. Antimicrob Agents Chemother. 2006:50(10):3457-9.

16. Huang YC, Hwang KP, Chen PY, Chen CJ, Lin TY. Prevalence of methicillinresistant Staphylococcus aureus nasal colonization among Taiwanese children in 2005 and 2006. J Clin Microbiol. 2007;45(12):3992-5.

17. Boyle-Vavra S, Ereshefsky B, Wang C-C, Daum RS. Successful multiresistant community-associated methicillin-resistant Staphylococcus aureus lineage from Taipei, Taiwan, that carries either the novel staphylococcal chromosome cassette mec (SCCmec) type VT or SCCmec type IV. J Clin Microbiol. 2005;43(9):4719-30.

18. Ito T, Ma XX, Takeuchi F, Okuma K, Yuzawa H, Hiramatsu K. Novel type V staphylococcal cassette chromosome mec driven by a novel cassette chromosome recombinase, ccrC. Antimicrob Agents Chemother. 2004;48(7): 2637-51.

19. Jarraud S, Mougel C, Thioulouse J, Lina G, Meugnier H, Forey F, et al. Relationships between Staphylococcus aureus genetic background, virulence factors, agr groups (alleles), and human disease. Infect Immun. 2002;70(2): 631-41.

20. Lina G, Piemont Y, Godail-Gamot F, Bes M, Peter M, Gauduchon V, et al. Involvement of Panton-Valentine leukocidin producing Staphylococcus aureus in primary skin infections and pneumonia. Clin Infect Dis. 1999;29(5): 1128-32.

21. Bannerman T, Hancock G, Tenover F, Miller J. Pulsed-field gel electrophoresis as a replacement for bacteriophage typing of Staphylococcus aureus. J Clin Microbiol. 1995;33(3):551-5.

22. Tenover FCAR, Goering RV, Mickelsen PA, Murray BE, Persing DH, Swaminathan B. Interpreting chromosomal DNA restriction patterns produced by pulsed-field gel electrophoresis: criteria for bacterial strain typing. J Clin Microbiol. 1995;33(9):2233-9

23. Enright MC, Day NPJ, Davies CE, Peacock SJ, Spratt BG. Multilocus sequence typing for characterization of methicillin-resistant and methicillin-susceptible clones of Staphylococcus aureus. J Clin Microbiol. 2000;38(3):1008-15.

24. Petrelli D, Repetto A, D'Ercole S, Rombini S, Ripa S, Prenna M, et al. Analysis of meticillin-susceptible and meticillin-resistant biofilm-forming Staphylococcus aureus from catheter infections isolated in a large Italian hospital. J Med Microbiol. 2008;57(3):364-72.

25. Reddy P, Qi C, Zembower T, Noskin GA, Bolon M. Postpartum mastitis and community-acquired methicillin-resistant Staphylococcus aureus. Emerg Infect Dis. 2007;13(2):298-301.

26. Wang JL, Chen SY, Wang JT, Wu GHM, Chiang WC, Hsueh P-R, et al. Comparison of both clinical features and mortality risk associated with bacteremia due to community-acquired methicillin-resistant Staphylococcus aureus and methicillin-susceptible S. aureus. Clin Infect Dis. 2008:46(6):799-806.

27. Cosgrove SE, Sakoulas G, Perencevich EN, Schwaber MJ, Karchmer AW, Carmeli Y. Comparison of mortality associated with methicillin-resistant and methicillin-susceptible Staphylococcus aureus bacteremia: a meta-analysis. Clin Infect Dis. 2003:36(1):53-9.

28. Miller LG, Perdreau-Remington F, Bayer AS, Diep B, Tan N, Bharadwa K, et al. Clinical and epidemiologic characteristics cannot distinguish communityassociated methicillin-resistant Staphylococcus aureus infection from methicillin-susceptible $S$. aureus infection: a prospective investigation. Clin Infect Dis. 2007;44(4):471-82.

29. Cosgrove SEMD, Qi YMD, Kaye KSMD, Harbarth SMD, Karchmer AWMD, Carmeli YMD. The impact of methicillin resistance in Staphylococcus aureus bacteremia on patient outcomes: mortality, length of stay, and hospital charges. Infect Control Hospl Epidem. 2005;26(2):166-74.

30. Aires de Sousa M, Crisostomo MI, Santos Sanches I, Wu JS, Fuzhong J, Tomasz A, et al. Frequent recovery of a single clonal type of multidrugresistant Staphylococcus aureus from patients in two hospitals in Taiwan and China. J Clin Microbiol. 2003:41(1):159-63.

31. Chen CJ, Huang YC, Chiu CH, Su LH, Lin TY. Clinical features and genotyping analysis of community-acquired methicillin-resistant Staphylococcus aureus infections in Taiwanese children. Pediatr Infect Dis J. 2005:24(1):40-5.

32. Monecke S, Slickers P, Ellington MJ, Kearns AM, Ehricht R. High diversity of Panton-Valentine leukocidin-positive, methicillin-susceptible isolates of Staphylococcus aureus and implications for the evolution of community- associated methicillin-resistant S. aureus. Clin Microbiol Infect. 2007;13(12): 1157-64.

33. Araj GF, Talhouk RS, Simaan CJ, Maasad MJ. Discrepancies between mecA PCR and conventional tests used for detection of methicillin resistant Staphylococcus aureus. Int J Antimicrob Agents. 1999;11(1):47-52.

34. Chen F-J, Huang I-W, Wang C-H, Chen P-C, Wang H-Y, Lai J-F, et al. mecAPositive Staphylococcus aureus with Low-Level Oxacillin MIC in Taiwan. J Clin Microbiol. 2012;50(5):1679-83.

35. Daum RS. Skin and soft-tissue infections caused by methicillin-resistant Staphylococcus aureus. N Engl J Med. 2007;357(4):380-90.

36. Naimi TS, LeDell KH, Como-Sabetti K, Borchardt SM, Boxrud DJ, Etienne J, et al. Comparison of community- and health care-associated methicillinresistant Staphylococcus aureus infection. JAMA. 2003;290(22):2976-84.

37. Okuma K, Iwakawa K, Turnidge JD, Grubb WB, Bell JM, O'Brien FG, et al. Dissemination of new methicillin-resistant Staphylococcus aureus clones in the community. J Clin Microbiol. 2002;40(1 1):4289-94.

38. Stevens DL, Bisno AL, Chambers HF, Everett ED, Dellinger P, Goldstein EJ, et al. Practice guidelines for the diagnosis and management of skin and softtissue infections. Clin Infect Dis. 2005;41(10):1373-406.

39. LaPlante KL, Rybak MJ, Amjad M, Kaatz GW. Antimicrobial susceptibility and staphylococcal chromosomal cassette mec type in community- and hospital-associated methicillin-resistant Staphylococcus aureus. Pharmacotherapy. 2007;27(1):3-10.

40. Chuck EA, Frazee BW, Lambert L, McCabe R. The benefit of empiric treatment for methicillin-resistant Staphylococcus aureus. J Emerg Med. 2010;38(5):567-71.

\section{Submit your next manuscript to BioMed Central and we will help you at every step:}

- We accept pre-submission inquiries

- Our selector tool helps you to find the most relevant journal

- We provide round the clock customer support

- Convenient online submission

- Thorough peer review

- Inclusion in PubMed and all major indexing services

- Maximum visibility for your research

Submit your manuscript at www.biomedcentral.com/submit
C Biomed Central 